\title{
Intestinal Perforation
}

National Cancer Institute

\section{Source}

National Cancer Institute. Intestinal Perforation. NCI Thesaurus. Code C39611.

A rupture in the wall of the small or large intestine due to traumatic or pathologic processes. 